\title{
Correction: Prevalence of self-reported tuberculosis, knowledge about tuberculosis transmission and its determinants among adults in India: results from a nation-wide cross-sectional household survey
}

Chandrashekhar T Sreeramareddy ${ }^{1 *}$, HN Harsha Kumar ${ }^{2}$ and John T Arokiasamy ${ }^{3}$

\section{Correction}

Following the publication of our article [1], we noticed that for calculation of prevalence rates (95\% confidence intervals) of self-reported tuberculosis (TB) shown in Table 1 we had not considered sampling weights of complex survey design used in India Demographic Health Survey (DHS). We have re-analysed the data including the sampling weights to calculate weighted prevalence rates and their 95\% CIs for self-reported TB in revised Table 1. The revised analysis was carried out using STATA/IC (version 10). The STATA code for revised analysis is available along with this correction article (Additional file 1). We request the readers to consider the corrected Table 1 shown here in place of Table 1 of the original manuscript [1]. In second paragraph of page five of original manuscript, an overall prevalence of self-reported TB should be read as 5.21 per 1000 participants. Revised analysis for Table 1 showed a clear gradient in prevalence of self-reported $\mathrm{TB}$ according to wealth index. For example, the richest had a lowest prevalence of self-reported TB (1.92 per 1000 population) and the poorest had the highest prevalence (10.5 per 1000 population). Chi square test was used to assess the statistical significance of the differences in weighted prevalence rates according to each demographic and socio-economic variables. The differences in weighted prevalence rates for all variables were statistically significant $(p<0.01)$. The readers should also consider the following additional statement in the conclusion: 'Economically deprived populations are at most risk of TB and should be targeted by TB control programs in India'. We apologise the readers for confusion caused due to wrong analysis and thank Dr. Jason Andrews for drawing our attention towards this error.

\footnotetext{
* Correspondence: chandrashekharats@yahoo.com

${ }^{1}$ Department of Clinical Sciences, Faculty of Medicine and Health Sciences, University Tunku Abdul Rahman, Sungai Long, Malaysia

Full list of author information is available at the end of the article
} 
Table 1 Weighted prevalence rates of self-reported tuberculosis among adult men (aged 15-59 years) and women (aged 15-49 years) by selected demographic and socio-economic characteristics

\begin{tabular}{|c|c|c|c|c|}
\hline & Sample (N) & Number reporting TB & Weighted prevalence per 1000 population & $95 \% \mathrm{Cls}$ \\
\hline Overall Prevalence & 198754 & 915 & 5.21 & $4.75,5.67$ \\
\hline \multicolumn{5}{|l|}{ Age } \\
\hline$\leq 25$ years & 72300 & 187 & 2.87 & $2.29,3.45$ \\
\hline $26-40$ years & 84639 & 423 & 5.65 & $4.94,6.35$ \\
\hline$>40$ years & 41815 & 305 & 8.33 & $7.02,9.64$ \\
\hline \multicolumn{5}{|l|}{ Gender } \\
\hline Male & 72369 & 443 & 7.12 & $6.21,8.04$ \\
\hline Female & 124385 & 472 & 4.06 & $3.57,4.55$ \\
\hline \multicolumn{5}{|l|}{ Type of residence } \\
\hline Urban & 95160 & 353 & 3.37 & $2.84,3.91$ \\
\hline Rural & 103594 & 562 & 6.16 & $5.51,6.8$ \\
\hline \multicolumn{5}{|l|}{ Education } \\
\hline No education & 50465 & 411 & 9.03 & $7.92,10.15$ \\
\hline Primary & 29230 & 160 & 5.12 & $4.03,6.21$ \\
\hline Secondary & 94627 & 308 & 3.21 & $2.69,3.73$ \\
\hline Higher & 24389 & 36 & 1.19 & $0.61,1.71$ \\
\hline \multicolumn{5}{|l|}{ Wealth quintiles } \\
\hline Poorest & 21162 & 119 & 10.52 & $8.84,12.21$ \\
\hline Poorer & 27930 & 192 & 6.94 & $5.67,8.21$ \\
\hline Middle & 38547 & 220 & 5.22 & $4.23,6.21$ \\
\hline Rich & 49482 & 185 & 2.99 & $2.33,3.66$ \\
\hline Richest & 61633 & 119 & 1.92 & $1.4,2.44$ \\
\hline \multicolumn{5}{|l|}{ Region of India } \\
\hline Northern India & 31584 & 89 & 3.87 & $2.85,4.89$ \\
\hline North-eastern India & 34776 & 233 & 7.43 & $5.50,9.36$ \\
\hline Central India & 37987 & 199 & 5.69 & $4.79,6.59$ \\
\hline Western India & 27707 & 126 & 5.3 & $4.17,6.43$ \\
\hline Eastern India & 24606 & 146 & 7.44 & $6.02,8.85$ \\
\hline South India & 42094 & 122 & 2.84 & $2.23,3.45$ \\
\hline
\end{tabular}

* Chi square test was statistically significant $(p<0.01)$ for all variables.

\section{Additional file}

Additional file 1: STATA code for revised analysis of Table 1.

\section{Author details}

${ }^{1}$ Department of Clinical Sciences, Faculty of Medicine and Health Sciences, University Tunku Abdul Rahman, Sungai Long, Malaysia. ${ }^{2}$ Department of Community Medicine, Kasturba Medical College, Mangalore, India. ${ }^{3}$ Department of Community Medicine, International Medical University, Kuala Lumpur, Malaysia.

\section{Reference}

1. Sreeramareddy $\mathrm{CT}$, Harsha Kumar HN, Arokiasamy JT: Prevalence of selfreported tuberculosis, knowledge about tuberculosis transmission and its determinants among adults in India: results from a nation-wide crosssectional household survey. BMC Infect Dis 2013, 13:16.

doi:10.1186/1471-2334-13-542

Cite this article as: Sreeramareddy et al:: Correction: Prevalence of selfreported tuberculosis, knowledge about tuberculosis transmission and its determinants among adults in India: results from a nation-wide cross-sectional household survey. BMC Infectious Diseases 2013 13:542.

Received: 6 June 2013 Accepted: 28 October 2013

Published: 14 November 2013 